\title{
Pelaksanaan Discharge Planning dengan kepuasan pasien (Studi di RSUD Sultan Imanudin Pangkalan Bun, Kotawaringin Barat, Kalimantan Tengah)
}

\author{
Taufiq Rahman ${ }^{1}$ Ni Wayan Rahayu Ningtyas ${ }^{2}$ Rastia Ningsih $^{3}$ \\ ${ }^{1}$ STIKes Insan Cendekia Medika Jombang ${ }^{23}$ STIKes Borneo Cendekia Medika \\ Pangkalan Bun \\ 1email : taufiqrahman@gmail.com, ${ }^{2}$ email : niwayanrahayu@gmail.com, ${ }^{3}$ email : \\ rastianingsih@gmail.com
}

\begin{abstract}
ABSTRAK
Pendahuluan Discharge planning keperawatan merupakan komponen yang terkait dengan rentang keperawatan, sering pula disebut dengan perawatan berkelanjutan yang artinya perawatan yang dibutuhkan oleh pasien dimanapun pasien berada. Kegagalan dalam memberikan perencanaan pulang akan beresiko terhadap beratnya penyakit, ancaman hidup dan disfungsi fisik. Oleh karena itu dalam perencanaan pulang atau discharge planning sangat penting, tujuan penelitian ini adalah untuk mengetahui hubungan antara pelaksanaan discharge planning dengan kepuasan pasien. Metode penelitian jenis penelitian ini adalah kuantitatif. dengan jumlah populasi 24. Sampel di ambil dari pasien yang dirawat di RSUD Sultan Imanudin Pangkalan Bun sebanyak 24 responden dengan teknik Quota Sampling Variabel dalam penelitian ini adalah hubungan antara pelaksanaan discharge planning dengan kepuasan pasien, instrumen penelitiannya mengguakan kuesioner, pengolahan data dengan Editing, Coding, Scoring, Tabulating, Uji Spearman Rank Data disajikan dalam bentuk distribusi frekuensi selanjutnya dianilisis secara dinamika,data yang di analasi meliputi univariat dan bivariat. Hasil penelitian berdasarkan hasil penelitian sebagian besar $17(70,8 \%)$ responden menjelaskan pelaksaan discharge planning dalam kategori baik, Sedangkan pelaksanaan discharge Planning yang tidak baik 7 (29,2\%), berdasarkan uji korelasi didapatkan nilai $\rho=0.000<0,05$, dengan demikian $\mathrm{H}_{0}$ ditolak dan $\mathrm{H}_{1}$ diterima, artinya ada hubungan pelaksanaan discharge Planning dengan kepuasan pasien. Kesimpulan pelaksanaan Discharge Planning di RSUD Sultan Imanudin Pangkalan Bun pada Tahun 2018 dapat di kategorikan sudah baik. Sebagian besar dari responden merasa sudah puas atas pelayanan yang diberikan oleh RSUD Sultan Imanudin pangkalan Bun tahun 2018.
\end{abstract}

Kata kunci : Pelaksanaan Discharge planning dengan kepuasan pasien

The implementation of discharge planning with patient satisfaction

(Study in The PROVINCIAL HOSPITAL Of Sultan Imanudin Base Bun, Kotawaringin Barat, Central Kalimantan)

\begin{abstract}
Preminilry: discharge planning of nursing is a component associated with a range of nursing, also referred to as continuous care means care required by patients wherever patients reside. Failure in providing planning return home will be at risk of the
\end{abstract}


disease, the severity of the threats against the life and physical dysfunction. Therefore, in planning the return home or discharge planning is very important, the goal of this research is to know the relation between the implementation of discharge planning with patient satisfaction. Redearch method: type of this research is quantitative. with a population of 24. Samples taken from patients who were treated at the PROVINCIAL HOSPITAL Sultan Base 24 Bun Imanudin respondents with engineering Quota Sampling Variables in this study is the relationship between the implementation of discharge planning patient satisfaction with his work in his own instrument, questionnaire, data processing with Coding, Editing, Scoring, Tabulating, Spearman Rank Test Data presented in the form of a frequency distribution of the next dianilisis in Dynamics, data in analasi includes Univariate and bivariat. Result and discussion: Based on the results of research most of the $17(70.8 \%)$ of respondents describe the pelaksaan discharge planning in the category either, while the implementation of discharge Planning is not a good 7 (29.2\%), based on a test of correlation obtained value $\mathrm{p}=0000<0.05, \mathrm{H} 0$ is rejected and thus $\mathrm{H} 1$ is accepted, this means that there is a discharge Planning implementation relationships with patient satisfaction. Conclusion: the implementation of Discharge Planning in the PROVINCIAL HOSPITAL of Sultan Imanudin Base Bun in the year 2018 may be categorized already good. The majority of respondents felt it was satisfied over the services provided by the HOSPITALS of the Sultan Imanudin the base year 2018 Bun.

Key words: Discharge planning with the Implementation of patient satisfaction

\section{PENDAHULUAN}

Rumah sakit adalah salah satu sarana pelayanan kesehatan yang sering dimanfaatkan oleh masyarakat dalam mencari bantuan terhadap permasalahan kesehatan yang dihadapi pasien (Kusnanto, 2004). Demam Berdarah Dengue (DBD) sampai saat ini masih merupakan masalah kesehatan baik bagi tenaga kesehatan khususnya, maupun masyarakat luas pada umumnya. Hal ini dikarenakan penyakit ini dapat menimbulkan wabah yang apabila penanganannya tidak tepat dapat mengakibatkan kematian. Penyakit ini disebabkan oleh virus dengue yang ditularkan oleh nyamuk dari family Flaviviridae yaitu Aedes aegepty,Aedes albopictus, dan beberapa spesies Aedes lainnya.Gejala klinis dari demam berdarah dengue bersifat dinamis dan terdiri dari tiga fase, yaitu fase febris, fase kritis dan fase penyembuhan. Walaupun sudah banyak hal positif yang telah dicapai dibidang pendidikan keperawatan, tetapi gambaran pengelolaan layanan keperawatan belum memuaskan.Layanan keperawatan masih sering mendapatkan keluhan masyarakat, terutama sikap perawat dan kemampuan perawat dalam memberikan asuhan keperawatan kepada klien.

Penelitian mengenai kepuasan pasien pernah di lakukan oleh hardiansyah (2006) di RSU Zainoel Abidin Banda Aceh terhadap 85 responden di dapat bahwa 51,8 \% pasien yang di nyatakan puas terhadap pelayanan RSU $\mathrm{Dr}$ 
Zainoel Abidin Banda Aceh, sedangkan selebihnya $48,2 \%$ pasien menyatakan tidak puas terhadap pelayanan keperawatan yang di terimanya.

Oleh karena itu petugas kesehatan memberikan komunikasi terapeutik kepada pasien sehingga klien merasa puas dan senang atas pelayanannya. Dalam tubuh manusia terdapat hormon endorfin. Hormon endorfin membuat orang merasa senang dan memiliki kekebalan tubuh, senyawa kimia ini diproduksi oleh tubuh saat orang merasa bahagia, juga cukup istirahat. Memiliki endorfin dalam kadar normal menimbulkan perasaan senang dan nyaman hingga membuat seseorang berenergi. Untuk mengantisipasi halhal yang tidak di inginkan menyangkut instalasi kesehatan maupun klien maka setiap instalasi atau pelayanan kesehatan perlu di terapkan adanya Discharge planning dengan menggunakan komunikasi terapeutik dengan baik agar pasien mau melaksanakanperintah perawat dalam hal minum obat dan menjaga kondisi badannya agar tetap sehat dan tidak kambuh kembali.

\section{METODE PENELITIAN}

penelitian ini menggunakan Nonprobability sampling yaitu teknik yang tidak memberi peluang yang sama bagi setiap anggota populasi untuk dipilih menjadi sample. Jenis penelitian yang digunakan adalahQuota Sampling yaitu pengambilan sample dilakukan terhadap anggota populasi yang mempunyai ciri-ciri tertentu sampai jumlah kuota yang diinginkan terpenuhi (Nursalam, 2003)
Sampel adalah sebagian atau wakil populasi yang diteliti. Sampel yang digunakan adalah pasien DBD rawat inap kelas III RSUD Sultan Imanudin Pangkalan Bun yang berjumlah 24 pasien. Instruman penelitian menggunakan lembar koesioner dan cek list, dimana variabel independen adalah pelaksanaan discharge planning dan variabel dependen adalah kepuasan pasien pada pasien DBD.

\section{HASIL PENELITIAN}

\section{Data umum}

Tabel 1 Distribusi responden berdasarkan jenis kelamin di RSUD Sultan Imanudin Pangkalan Bun Tahun 2018.

\begin{tabular}{lll}
\hline $\begin{array}{l}\text { Jenis } \\
\text { Kelamin }\end{array}$ & Jumlah & $\begin{array}{l}\text { Persentase } \\
(\%)\end{array}$ \\
\hline Laki-laki & 14 & $58,3 \%$ \\
Perempuan & 10 & $41,7 \%$ \\
\hline Total & 24 & $100 \%$ \\
\hline
\end{tabular}

Sumber: Data primer, 2018

Pada tabel 1 Menunjukan bahwa sebagian besar responden berjenis kelamin laki-laki sebanyak 14 orang $(58,3 \%)$.

Tabel 2 Distribusi responden berdasarkan usia di RSUD Sultan Imanudin Pangkalan Bun tahun 2018

\begin{tabular}{|c|c|c|}
\hline $\begin{array}{l}\text { Umur } \\
\text { (Tahun) }\end{array}$ & Jumlah & $\begin{array}{l}\text { Persentase } \\
(\%)\end{array}$ \\
\hline $\begin{array}{l}17-33 \\
\text { tahun }\end{array}$ & 8 & $33,3 \%$ \\
\hline $\begin{array}{l}34-40 \\
\text { thun }\end{array}$ & 12 & $50 \%$ \\
\hline $\begin{array}{l}>41 \\
\text { tahun }\end{array}$ & 4 & $16,7 \%$ \\
\hline Total & 24 & $\%$ \\
\hline
\end{tabular}


Pada tabel 2 Menunjukan bahwa separuh responden berumur 34-40 tahun sebanyak 12 orang (50\%).

Tabel 3 Distribusi responden berdasarkan pekerjaan di RSUD Sultan Imanudin Pangkalan Bun tahun 2018

\begin{tabular}{lll}
\hline Pekerjaan & Jumlah & $\begin{array}{l}\text { Persentase } \\
(\%)\end{array}$ \\
\hline Buruh & 16 & $66,7 \%$ \\
PNS & - & $-\%$ \\
Swasta & - & $-\%$ \\
Wiraswasta & - & $-\%$ \\
IRT & 8 & $33,3 \%$ \\
\hline Total & 24 & $100 \%$ \\
\hline Sumber: Data primer, 2018
\end{tabular}

Tabel 4 Distribusi responden berdasarkan pendidikan terakhir di RSUD Sultan Imanudin Pangkalan Bun tahun 2018

\begin{tabular}{lll}
\hline Pendidikan & Jumlah & $\begin{array}{l}\text { Persentase } \\
(\%)\end{array}$ \\
\hline Tidak & - & $-\%$ \\
tamat SD & & $16,7 \%$ \\
SD & 4 & $33,3 \%$ \\
SMP & 8 & $50 \%$ \\
SMA & 12 & $-\%$ \\
PT & - & $100 \%$ \\
\hline Total & 24 & \multicolumn{2}{l}{ Sumber: Data primer, 2018}
\end{tabular}

Pada tabel 4 Menunjukan bahwa separuh responden berpendidikan terakhir SMA sebanyak 12 orang $(50 \%)$.

\section{Data khusus}

Tabel 5 Distribusi Frekuensi Pelaksanaan Discharge Planning di RSUD Sultan Imanudin Pangkalan Bun Tahun 2018.

\begin{tabular}{llll}
\hline & Pelaksanaa & & \\
$\mathrm{N}$ & $\mathrm{n}$ & Frekwens & Persentase $(\%$ \\
$\mathrm{o}$ & Discharge & $\mathrm{i}$ & ) \\
& Planning & & \\
\hline 1. & Baik & 17 & 70,8 \\
2. & Tidak baik & 7 & 29,2 \\
\hline \multicolumn{2}{l}{ Total } & 24 & 100,00 \\
\hline
\end{tabular}

Sumber data : Data Primer, 2018.

Berdasarkan Tabel 5di atas menunjukkan bahwa sebagian besar 17 $(70,8 \%)$ responden pelaksaan discharge planning dalam kategori baik.

Tabel 6 Distribusi Frekuensi Kepuasan Pasien di RSUD Sultan Imanudin Pangkalan Bun Tahun 2018.

\begin{tabular}{llll}
\hline No & $\begin{array}{l}\text { Kepuasan } \\
\text { Pasien }\end{array}$ & Frekwensi & Persentase(\%) \\
\hline 1. & Sangat & 2 & $8,3 \%$ \\
2. & puas & 19 & $79,2 \%$ \\
3. & Puas & 3 & $12,5 \%$ \\
4. & Tidak & - & - \\
& puas & & \\
& Sangat & \\
& Tidak & & \\
& puas & & $100 \%$ \\
\hline & & 24 & 2018
\end{tabular}

Sumber data : Data Primer, 2018.

Berdasarkan Tabel 6 di atas menunjukkan sebagian besar $19(79,2)$ responden merasa puas.

Tabel 7 Distribusi Responden Berdasarkan Pelaksanaan Discharge Planning dengan Kepuasan Pasien di RSUD Sultan Imanudin Pangkalan Bun Tahun 2018. 


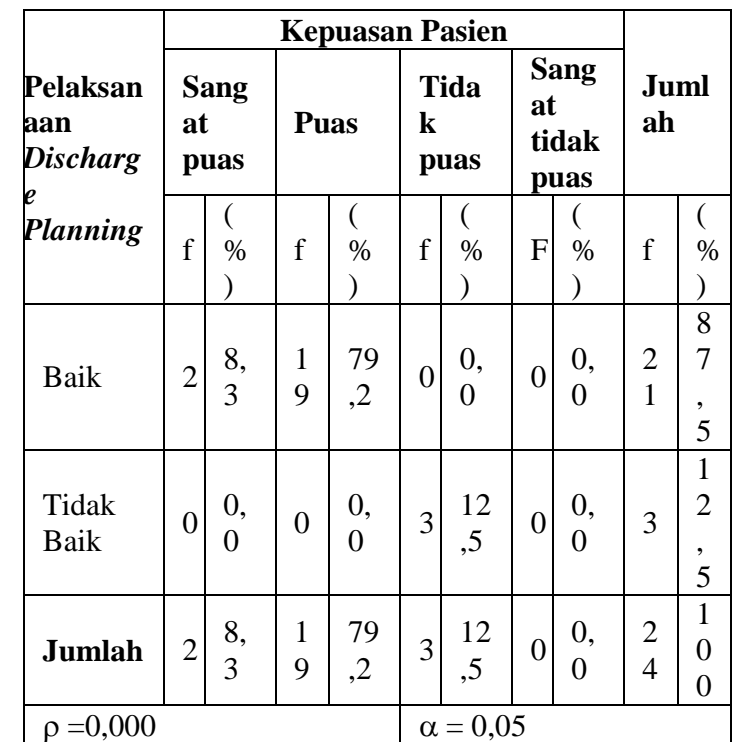

Sumber data : Data Primer, 2018

Berdasarkan tabel 5.7 di atas menunjukkan bahwa pelaksanaan Discharge Planning yang baik 21 orang, terdiri dari sebagian besar 19 $(79,2)$ responden merasa puas, dan sebagian kecil $2(8,3 \%)$ responden merasa sangat puas, dan sebagian kecil $3(12,5)$ responden merasa tidak puas.

Hasil Uji korelasi rank spearman untuk menguji hubungan pelaksanaan discharge Planning dengan kepuasan pasien di RSUD Sultan Imanudin Pangkalan Bun dengan menggunakan perhitungan SPSS didapatkan nilai $\rho=$ $0.000<0,05$, dengan demikian $\mathrm{H}_{0}$ ditolak dan $\mathrm{H}_{1}$ diterima, artinya ada hubungan pelaksanaan discharge Planning dengan kepuasan pasien di RSUD Sultan Imanudin Pangkalan Bun.

\section{PEMBAHASAN}

Pada tabel 5 menunjukkan bahwa sebagian besar $17(70,8 \%)$ responden pelaksaan discharge planning dalam kateogri baik, dan sebagian kecil7 $(29,9 \%)$ pelaksanaan discharge planning dalam kateogri tidak baik.
Hasil analisis dari data kepuasan pasien terdapat 5 (lima) indicator yaitu pengobatan dirumah diperoleh data persentase $23,7 \%$, penggunaan obat diperoleh data persentase $19,9 \%$,pengobatan selanjutnya diperoleh data persentase $19,9 \%$, gaya hidup dan batasan aktivitas diperoleh data persentase $18,2 \%$, dan petunjuk perawatan diri diperoleh data persentase $18,2 \%$.

Berdasarkan hasil penelitian dan kajian teori yang telah diuraikan, maka pelaksanaan Discharge Planning yang dilakukan oleh klien bersama perawat di RSUD Sultan Imanudin Pangkalan Bun terdapat sebagian besar 17 $(70,8 \%)$, dan pada indicator nilai tertinggi diperoleh $23,7 \%$ pada pengobatan dirumah. Dari data di atas menggambarkan pola pelaksanaan discharge planning yang sudah baik. Hal ini memberikan gambaran bahwa terjadi komunikasi yang baik antara perawat dengan pasien dalam hal pelaksanaan discharge planning. Tindakan keperawatan yang dilakukan perawat dalam hal discharge planning telah sesuai dengan langkah-langkah penerapan proses keperawatan yang menjadi tanggung jawab perawat. Faktor kunci keberhasilan discharge planning di RSUD Sultan Imanudin Pangakalan Bun sangat ditentukan oleh perawat yang juga dipengaruhi oleh faktor motivasi yang berkaitan dengan ciri pribadi perawat.

Pada tabel 6 menunjukkan bahwa sebagian besar $19(79,2 \%)$ responden merasa puas, dan sebagian kecil 2 $(8,3 \%)$ responden merasa sangat puas dan $3(12,5)$ merasa tidak puas dengan pelaksanaan discharge planning.

Hasil analisis dari data kepuasan pasien terdapat 5 (lima) indicator yaitu tangible (nyata) diperoleh data persentase $20,9 \%$, reliability 
(kehandalan) diperoleh data persentase $20,1 \%$, emphaty (perhatian) diperoleh data persentase $20,1 \%$, assurance (jaminan) diperoleh data persentase $19,5 \%$, dan responsiveness diperoleh data persentase $(19,3)$.Dari data di atas bahwa kepuasan sebagian besar kepuasan pasien terdapat pada indicator tangible (nyata).

Berdasarkan hasil penelitian yang telah diuraikan, maka kepuasan pasien yang dilakukan oleh klien bersama perawat di RSUD Sultan Imanudin Pangkalan Bun sebagian besar $19 \quad(79,2 \%)$ respoden merasa puas, dan pada indicator nilai tertinggi diperoleh $20,9 \%$ pada tangible (nyata).

Hasil penelitian tentang hubungan pelaksanaan discharge planning dengan kepuasan pasien menunjukkan bahwa pelaksanaan discharge Planning yang baik 21 orang, terdiri dari sebagian besar $19(79,2 \%)$ merasa puas dan sebagian kecil $2(8,3 \%)$ responden merasa sangat puas dan $3(12,5 \%)$ responden merasa tidak puas. Hasil ini menggambarkan bahwa ada hubungan pelaksanaan dengan kepuasan pasien di RSUD Sultan Imanudin Pangkalan Bun.

Berdasarkan hasil penelitian dan kajian teori yang telah diuraikan, maka proses pelaksanaan Discharge Planning diRSUD Sultan Imanudin Pangkalan Bun berpengaruh terhadap kepausan pasien. Bila pelaksanaan discharge Planning berjalan dengan baik, maka sudah barang tentu pasien akan terpuaskan, sebaliknya jika pelaksanaan discharge planning di RSUD Sultan Imanudin Pangkalan Bun tidak baik maka pasien merasa tidak puas. Jika dalam kinerjanya perawat dalam melakukan prosedur discharge planning di RSUD Sultan Imanudin Pangkalan Bun dapat dilaksanakan oleh perawat dengan baik, maka keberhasil discharge planning di RSUD Sultan Imanudin Pangkalan Bun akan berjalan dengan baik bila discharge planning telaksana dengan baik, dimana perawat dan juga klien mampu bersinergi mengikuti prosedur discharge planning, dimana unsure-unsur discharge planning mampu terpenuhi dengan baik, baik sejak waktu penerimaan klien, pengkajian kebutuhan klien, kajian faktor-fakor lingkungan, adanya kolaborasi dengan dokter dan disiplin ilmu, kajian penerimaan terhadap masalah kesehatan dan larangan yang berhubungan dengan masalah kesehatan, konsultasi dengan anggota tim kesehatan lain tentang kebutuhan klien, penetapan diagnose keperawatan dan rencana keperawatan yang kesemuanya harus berjalan sesuai prosedur. Bila hal ini terpenuhi secara keseluruhan maka kepuasan pasien akan didapatkan.

Pengajaran pada klien dan pemberi pelayanan lain merupakan tanggung jawab bagi seluruh anggota tim kesehatan. Perawat mempunyai tanggung jawab utama untuk memberikan perintah pada klien tentang sifat masalah kesehatan, hal-hal yang harus dihindari, penggunaan obatobat di rumah, jenis komplikasi dan sumber bantuan yang tersedia (Potter \& Perry, 2005).

\section{KESIMPULAN}

1. Pelaksanaan Discharge Planning diRSUD Sultan Imanudin Pangkalan Bunpada Tahun 2018 dapat di kateogrikan sudah baik.

2. Sebagian besar dari responden merasa sudah puas atas pelayanan discharge planning yang diberikan oleh RSUD Sultan Imanudin Pangkalan Bun Tahun 2018. 
3. Ada hubungan pelaksanaan discharge Planning dengan kepuasan pasien studi di RSUD Sultan Imanudin Pangkalan Bun Tahun 2018.

\section{KEPUSTAKAAN}

Hardiansyah (2006). Penelitian mengenai kepuasan pasien.

Kusnanto. (2004). Pengertian rumah sakit. Jakarta EGC

Pedoman Skripsi, Tesis dan Instrumen Penelitian Keperawatan. Jakarta : Salemba Medika.

Potter \& Perry. (2005). Buku Ajar Fundamental Keperawatan Konsep, Proses, dan Praktik Volume 1. Alih bahasa: Yasmin Asih et al. Edisi 4. Jakarta: EGC.

Nursalam. 2003. Konsep dan Penerapan Metodologi Penelitian Ilmu Keperawatan 